PREPARED FOR THE U.S. DEPARTMENT OF ENERGY, UNDER CONTRACT DE-AC02-76CH03073

PPPL-3580

PPPL-3580

UC-70

Effects of Radial Electric Fields on ICRF Waves

C.K. Phillips, J.C. Hosea, M. Ono, and J.R. Wilson

June 2001

M

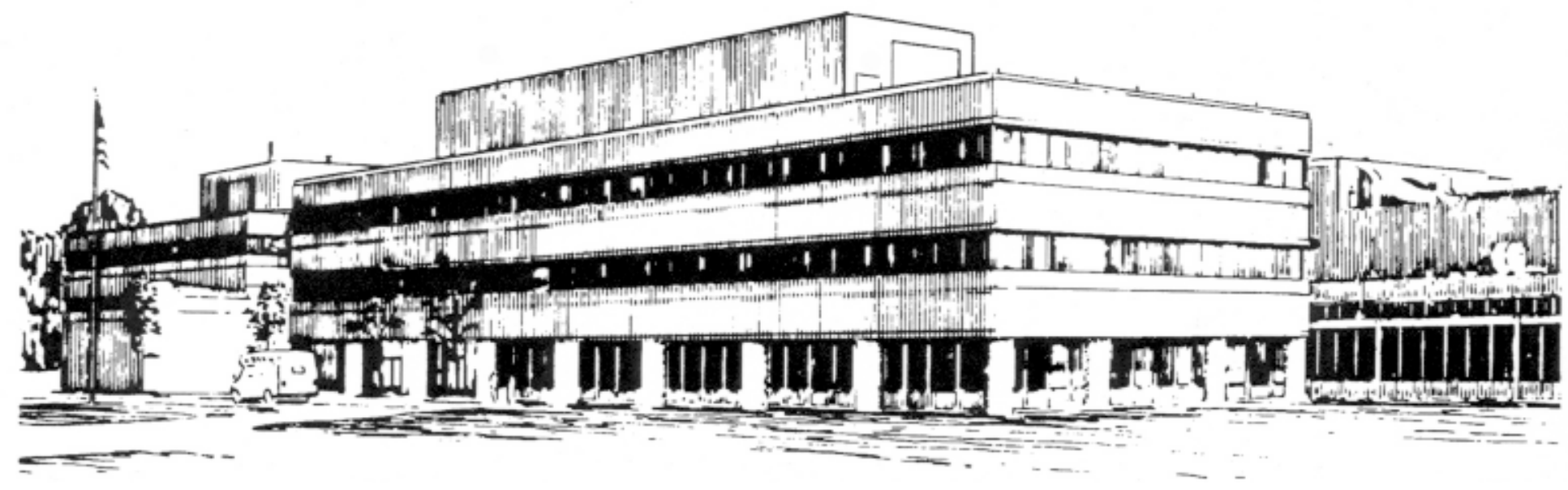

PRINCETON PLASMA PHYSICS LABORATORY PRINCETON UNIVERSITY, PRINCETON, NEW JERSEY 


\section{PPPL Reports Disclaimer}

This report was prepared as an account of work sponsored by an agency of the United States Government. Neither the United States Government nor any agency thereof, nor any of their employees, makes any warranty, express or implied, or assumes any legal liability or responsibility for the accuracy, completeness, or usefulness of any information, apparatus, product, or process disclosed, or represents that its use would not infringe privately owned rights. Reference herein to any specific commercial product, process, or service by trade name, trademark, manufacturer, or otherwise, does not necessarily constitute or imply its endorsement, recommendation, or favoring by the United States Government or any agency thereof. The views and opinions of authors expressed herein do not necessarily state or reflect those of the United States Government or any agency thereof.

\section{Availability}

This report is posted on the U.S. Department of Energy's Princeton Plasma Physics Laboratory Publications and Reports web site in Calendar Year 2001. The home page for PPPL Reports and Publications is: http://www.pppl.gov/pub_report/

DOE and DOE Contractors can obtain copies of this report from:

U.S. Department of Energy

Office of Scientific and Technical Information

DOE Technical Information Services (DTIS)

P.O. Box 62

Oak Ridge, TN 37831

Telephone: (865) 576-8401

Fax: (865) 576-5728

Email: reports@adonis.osti.gov

This report is available to the general public from:

National Technical Information Service

U.S. Department of Commerce

5285 Port Royal Road

Springfield, VA 22161

Telephone: 1-800-553-6847 or

(703) 605-6000

Fax: (703) 321-8547

Internet: http://www.ntis.gov/ordering.htm 


\title{
Effects of Radial Electric Fields on ICRF Waves
}

\author{
C.K. Phillips, J.C. Hosea, M. Ono and J.R. Wilson
}

Princeton Plasma Physics Lab, Princeton NJ, 08543

\begin{abstract}
Equilibrium considerations infer that large localized radial electric fields are associated with internal transport barrier structures in tokamaks and other toroidal magnetic confinement configurations. In this paper, the effects of an equilibrium electric field on fast magnetosonic wave propagation are considered in the context of a cold plasma model.
\end{abstract}

\section{INTRODUCTION}

In recent years, enhanced confinement regimes characterized by large localized pressure gradients and sheared rotational velocity profiles have been observed in many tokamaks. Equilibrium considerations indicate that large localized radial electric fields are associated with these internal transport barrier (ITB) structures. In particular, if the pressure and rotational velocity profiles for a given species are known, then the equilibrium electric field can be inferred from:

$$
\overrightarrow{\mathrm{E}}+\overrightarrow{\mathrm{v}} \times \overrightarrow{\mathrm{B}}=\nabla \mathrm{p}
$$

In experiments on TFTR in which an ITB was formed using co-dominated neutral beam-driven toroidal rotation, significant localized radial electric fields on the order of $7 \times 10^{4} \mathrm{~V} / \mathrm{m}$ were inferred [1]. These equilibrium electric fields were localized to a region centered near r/a $\sim 0.3$, with a radial extent of $\pm 20 \%$ of the minor radius. Radially-varying equilibrium electric fields on the order of $3 \times 10^{4} \mathrm{~V} / \mathrm{m}$ have also been inferred in the core of $\mathrm{H}$-mode discharges on C-Mod which were heated with fast magnetosonic waves in the ion cyclotron range of frequencies (ICRF) [2]. In the Electric Tokamak (ET) device at UCLA, radial electric fields generated by rf-induced fast ion loss will be utilized to drive poloidal rotation and thereby induce the formation of a "global H-mode" [3]. Based on gyrokinetic simulations, radial electric fields with magnitudes on the order of $3 \times 10^{3} \mathrm{~V} / \mathrm{m}$ should be sufficient to suppress ion temperature gradient turbulence in ET and improve confinement [4]. Preliminary calculations indicate that equilibrium electric fields on the order of those observed in tokamaks may be present in some NSTX discharges [5].

The propagation and absorption of radio frequency waves in quasineutral plasmas has traditionally been determined assuming that there are no significant equilibrium electric fields present in the plasma. However, in the presence of equilibrium electric 
fields, the particle orbits are modified and equilibrium velocity flows arise. Hence, the dielectric properties of the plasma may be altered. It has been shown previously by Ganguli, Lee and Palmadesso using kinetic models that nonuniform electric fields perpendicular to ambient uniform magnetic fields can drive electrostatic ion cyclotron instabilities in the earth's ionosphere and magnetosphere [6]. In this paper the effects of an equilibrium radial electric field on fast magnetosonic wave propagation in toroidal magnetic confinement devices will be considered in the context of a locally uniform cold plasma model. Kinetic corrections and effects of nonuniform electric fields will be considered in future work.

\section{MODIFIED COLD PLASMA DIELECTRIC TENSOR}

The simplest model that can be used to examine effects of an equilibrium electric field on electromagnetic wave dynamics in quasineutral plasmas is a locally uniform cold plasma description. With the equilibrium magnetic field oriented in the $\hat{z}$ direction and the equilibrium electric field oriented in the $\hat{x}$ direction, the linearized cold fluid equation of motion for species, s, can be written in the form [7]:

$$
\begin{aligned}
\mathrm{n}_{\mathrm{s}} \mathrm{m}_{\mathrm{s}} \frac{\mathrm{d} \overrightarrow{\mathrm{v}}_{\mathrm{s}}}{\mathrm{dt}}=\mathrm{n}_{\mathrm{s}}\left(\mathrm{q}_{\mathrm{s}} \overrightarrow{\mathrm{E}}_{0}+\frac{\mathrm{q}_{\mathrm{s}}}{\mathrm{c}} \overrightarrow{\mathrm{V}}_{\mathrm{d}} \times \overrightarrow{\mathrm{B}}_{0}+\right. \\
\left.\mathrm{q}_{\mathrm{s}} \overrightarrow{\mathrm{E}}_{1}+\frac{\mathrm{q}_{\mathrm{s}}}{\mathrm{c}} \overrightarrow{\mathrm{v}}_{1 \mathrm{~s}} \times \overrightarrow{\mathrm{B}}_{0}+\frac{\mathrm{q}_{\mathrm{s}}}{\mathrm{c}} \overrightarrow{\mathrm{V}}_{\mathrm{d}} \times \overrightarrow{\mathrm{B}}_{1}\right)
\end{aligned}
$$

where $\overrightarrow{\mathrm{B}}=\mathrm{B}_{0} \hat{\mathrm{z}}+\overrightarrow{\mathrm{B}}_{1}, \overrightarrow{\mathrm{E}}=\mathrm{E}_{0} \hat{\mathrm{x}}+\overrightarrow{\mathrm{E}}_{1}$, and $\overrightarrow{\mathrm{v}}_{\mathrm{s}}=\overrightarrow{\mathrm{V}}_{\mathrm{d}}+\overrightarrow{\mathrm{v}}_{\mathrm{s} 1}$. The perturbed wave fields and particle velocities are assumed to have a wave-like dependence in the form $\vec{E}_{1}=\vec{E}_{1} e^{i(\vec{k} \cdot \vec{x}-\omega t)}$, and similarly for $\vec{B}_{1}, \vec{v}_{1}$. In the unperturbed steady state, the first two terms on the right hand side of Equation (2) must balance, indicating that the unperturbed plasma is drifting with the $\vec{E} \times \vec{B}$ velocity:

$$
\vec{V}_{d}=\frac{c \vec{E}_{0} \times \vec{B}_{0}}{B_{0}^{2}}=V_{d} \hat{y}=-\frac{c E_{0}}{B_{0}} \hat{y}
$$

For the simple uniform plasma model considered here, the equilibrium drift speed is a constant, so a transformation to a moving coordinate system could be utilized. However, in general the experimentally observed equilibrium electric fields are nonuniform, so inclusion of this non-uniformity would entail the use of spatially dependent frame transformations. Hence, in order to apply this model locally to a radially inhomogeneous tokamak plasma, the wave dynamics will be calculated in the "laboratory" frame to avoid these complications.

By combining the first order terms in Equation (2) with the linearized Maxwell equations, the perturbed velocity for each species can be expressed in terms of equilibrium quantities, wave parameters, and the wave electric field. Finally, the perturbed plasma current, which constitutes the response of the plasma to the applied 
wave fields, can be constructed from two terms, one arising directly from the wavedriven velocities and one arising from the zeroth order flow:

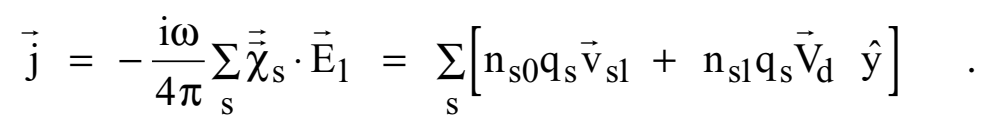

In this expression, the perturbed density, $\mathrm{n}_{\mathrm{s} 1}$, obtained from the continuity equation, is given by:

$$
\mathrm{n}_{\mathrm{s} 1}=\mathrm{n}_{\mathrm{s} 0} \frac{\overrightarrow{\mathrm{k}} \cdot \overrightarrow{\mathrm{v}}_{\mathrm{s} 1}}{\omega_{*}} \text {, where } \omega_{*}=\omega-\mathrm{k}_{\mathrm{y}} \mathrm{V}_{\mathrm{d}} \text {. }
$$

Solving Equation (4) for the susceptibility for each species, one finds:

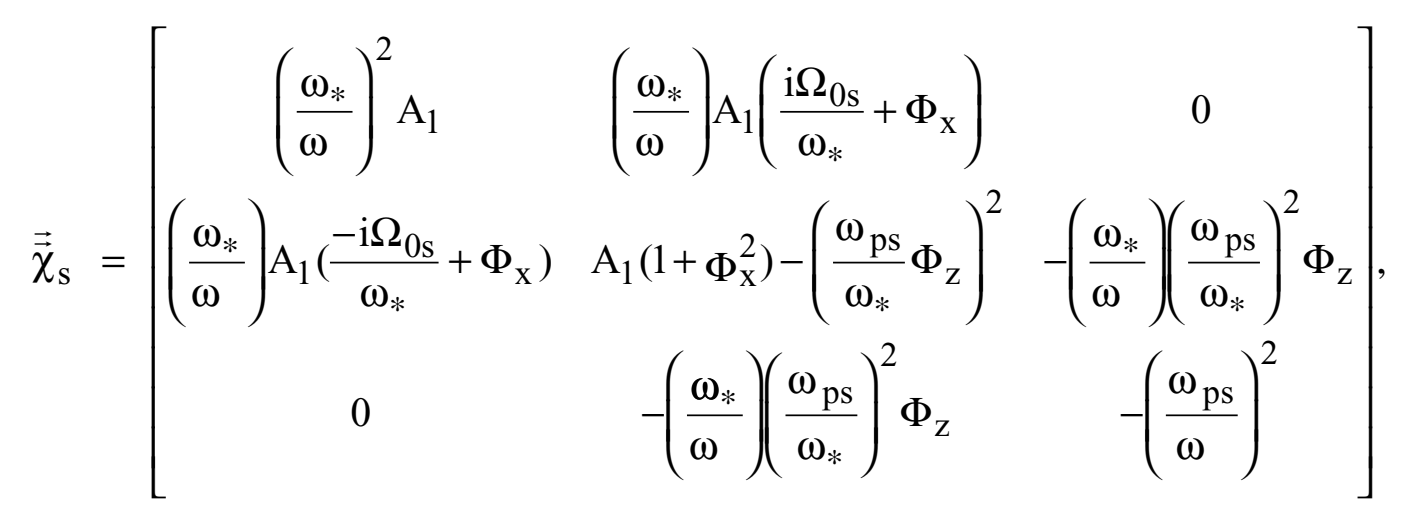

where $A_{1}=-\frac{\omega_{p s}^{2}}{\omega_{*}^{2}-\Omega_{0 s}^{2}}, \Omega_{0 s}=\frac{q_{s} B_{0}}{m_{s} c}$, and $\Phi_{i}=\frac{k_{i} V_{d}}{\omega}$, for $i=x, y, z$. The cold plasma dielectric tensor, generalized to include the effects of the equilibrium electric fields, is finally given by $\overrightarrow{\vec{\varepsilon}}=\overrightarrow{\overrightarrow{1}}+\sum_{\mathrm{s}} \overrightarrow{\vec{\chi}}_{\mathrm{s}}$. Note that the modified susceptibility reduces to the conventional form [7] when the electric-field induced equilibrium drift speed vanishes.

\section{DISCUSSIONS AND FUTURE WORK}

The modified cold plasma dielectric tensor given in Equation (6) is hermitian for real $\omega, \overrightarrow{\mathrm{k}}$ so no new damping or instability mechanisms have been introduced in this approximation. However, the modified dielectric tensor elements now depend on the wave vector components. Furthermore, in some of the terms that lead to resonances and cutoffs in the conventional cold plasma model, the wave frequency appears in the Doppler-shifted form, $\omega_{*}=\omega-\mathrm{k}_{\mathrm{y}} \mathrm{V}_{\mathrm{d}}$. The equilibrium magnetic field in a tokamak has both poloidal and toroidal components, so the equilibrium $\overrightarrow{\mathrm{E}} \times \overrightarrow{\mathrm{B}} \mathrm{drift}$ velocity also has both poloidal and toroidal components. In TFTR and C-Mod, typical toroidal rotation speeds are on the order of $10^{5} \mathrm{~m} / \mathrm{s}[1,2]$ and typical toroidal wave 
vector components are on the order of $10 \mathrm{~m}^{-1}$. For these experiments, the electric field induced Doppler shift is on the order of $1 \mathrm{MHz}$ - a value small compared to the launched wave frequencies of $30-80 \mathrm{MHz}$ in these devices. Hence, corrections to the cold plasma wave dynamics due to an equilibrium electric field appear to be small in conventional tokamaks. However, the corrections in low magnetic field devices such as NSTX or ET could prove to be larger, since the ion cyclotron frequency is on the

order of a few $\mathrm{MHz}$ in these devices. Finally, spatially localized electric fields perpendicular to ambient magnetic fields have been shown to destabilize electrostatic ion cyclotron waves [6]. Therefore, in future studies, the effects of spatially localized electric fields on the propagation and absorption of fast magnetosonic waves will be explored using kinetic models.

\section{ACKNOWLEDGMENTS}

The authors wish to acknowledge fruitful discussions with the late T.H. Stix on this subject. This work is supported by DOE contract DE-AC02-76CH03073.

\section{REFERENCES}

1. Synakowski, E.J. et al., Phys. Plasmas 4, 1736-1744 (1997).

2. Rice, J.E. et al., Nuclear Fusion 38, 75-85 (1998).

3. Taylor, R.J., et al., Bull. Am. Phys. Soc. 43, 1825 (1998).

4. M.W. Kissick et al., Phys. Plasmas 6, 4722 -4727 (1999).

5. Bourdelle, C., private communication.

6. Ganguli, G., Lee, Y.C. and Palmadesso, P., Phys. Fluids 28, 761-764 (1985).

7. Stix, T.H., Waves in Plasmas, AIP, NY, 1992, Chapter 1. 


\section{External Distribution}

Plasma Research Laboratory, Australian National University, Australia

Professor I.R. J ones, Flinders University, Australia

Professor J oão Canalle, Instituto de Fisica DEQ/IF - UERJ , Brazil

Mr. Gerson O. Ludwig, Instituto Nacional de Pesquisas, Brazil

Dr. P.H. Sakanaka, Instituto Fisica, Brazil

The Librarian, Culham Laboratory, England

Library, R61, Rutherford Appleton Laboratory, England

Mrs. S.A. Hutchinson, JET Library, England

Professor M.N. Bussac, Ecole Polytechnique, France

Librarian, Max-Planck-Institut für Plasmaphysik, Germany

J olan Moldvai, Reports Library, MTA KFKI-ATKI, Hungary

Dr. P. Kaw, Institute for Plasma Research, India

Ms. P.J . Pathak, Librarian, Insitute for Plasma Research, India

Ms. Clelia De Palo, Associazione EURATOM-ENEA, I taly

Dr. G. Grosso, Instituto di Fisica del Plasma, Italy

Librarian, Naka Fusion Research Establishment, J AERI, J apan

Library, Plasma Physics Laboratory, Kyoto University, J apan

Research Information Center, National Institute for Fusion Science, J apan

Dr. O. Mitarai, Kyushu Tokai University, J apan

Library, Academia Sinica, Institute of Plasma Physics, People's Republic of China

Shih-Tung Tsai, Institute of Physics, Chinese Academy of Sciences, People's Republic of China

Dr. S. Mirnov, TRINITI, Troitsk, Russian Federation, Russia

Dr. V.S. Strelkov, Kurchatov Institute, Russian Federation, Russia

Professor Peter Lukac, Katedra Fyziky Plazmy MFF UK, Mlynska dolina F-2, Komenskeho Univerzita, SK-842 15 Bratislava, Slovakia

Dr. G.S. Lee, Korea Basic Science Institute, South Korea

Mr. Dennis Bruggink, Fusion Library, University of Wisconsin, USA

Institute for Plasma Research, University of Maryland, USA

Librarian, Fusion Energy Division, Oak Ridge National Laboratory, USA

Librarian, Institute of Fusion Studies, University of Texas, USA

Librarian, Magnetic Fusion Program, Lawrence Livermore National Laboratory, USA

Library, General Atomics, USA

Plasma Physics Group, Fusion Energy Research Program, University of California at San Diego, USA

Plasma Physics Library, Columbia University, USA

Alkesh Punjabi, Center for Fusion Research and Training, Hampton University, USA

Dr. W.M. Stacey, Fusion Research Center, Georgia Institute of Technology, USA

Dr. J ohn Willis, U.S. Department of Energy, Office of Fusion Energy Sciences, USA

Mr. Paul H. Wright, Indianapolis, Indiana, USA 
The Princeton Plasma Physics Laboratory is operated by Princeton University under contract with the U.S. Department of Energy.

\author{
Information Services \\ Princeton Plasma Physics Laboratory \\ P.O. Box 451 \\ Princeton, NJ 08543
}

Phone: 609-243-2750

Fax: 609-243-2751

e-mail: pppl_info@pppl.gov

Internet Address: http://www.pppl.gov 